\title{
Azelnidipine plus olmesartan versus amlodipine plus olmesartan on arterial stiffness and cardiac function in hypertensive patients: a randomized trial
}

This article was published in the following Dove Press journal:

Drug Design, Development and Therapy

21 March 2013

Number of times this article has been viewed

\author{
Takeshi Takami' \\ Yoshihiko Saito ${ }^{2}$ \\ 'Department of Internal Medicine, \\ Clinic Jingumae, Kashihara, Japan; \\ ${ }^{2}$ First Department of Internal \\ Medicine, Nara Medical University, \\ Kashihara, Japan
}

Purpose: To compare the long-term effects of olmesartan combined with either azelnidipine or amlodipine on central blood pressure (CBP), left ventricular (LV) mass index (LVMI), LV diastolic function ( $\mathrm{e}^{\prime}$ velocity, E/e' ratio, E/A ratio) and arterial stiffness (brachial-ankle pulse wave velocity [baPWV] and augmentation index normalized for a heart rate of $75 \mathrm{bpm}$ [AIx]).

Patients and methods: Patients with systolic BP $\geq 140 \mathrm{mmHg}$ and/or diastolic BP $\geq 90 \mathrm{mmHg}$ received olmesartan monotherapy ( $20 \mathrm{mg} /$ day) for 12 weeks. They were then randomly assigned to fixed-dose add-on therapy with azelnidipine $(16 \mathrm{mg} /$ day; $\mathrm{n}=26)$ or amlodipine $(5 \mathrm{mg} /$ day; $\mathrm{n}=26$ ) for a further 2 years. CBP, LVMI, e' velocity, E/e' ratio, E/A ratio, baPWV, and AIx were measured at baseline, 6 months, and 2 years.

Results: Baseline characteristics of both groups were similar. The decrease in brachial BP over 2 years was similar in both groups. CBP, LVMI, E/e' ratio, baPWV, and AIx decreased significantly, and the E/A ratio and $\mathrm{e}^{\prime}$ velocity increased significantly in both groups. The decreases in CBP $(P<0.001)$, AIx $(P<0.001)$, baPWV $(P<0.001)$, LVMI $(P<0.001)$, and E/e' $(P=0.002)$ as well as the increase in $\mathrm{E} / \mathrm{A}$ ratio $(P=0.03)$ over 2 years were significantly greater in the olmesartan/azelnidipine group than in the olmesartan/amlodipine group. Multivariate linear regression analyses showed that the changes in baPWV $(\beta=0.41, P<0.001)$ and CBP ( $\beta=0.47, P=0.01$ ) were independently associated with the change in LVMI, the change in baPWV ( $\beta=0.25, P<0.001$ ) was independently associated with the change in E/e' ratio, and the changes in baPWV $(\beta=0.21, P=0.001)$ and AIx $(\beta=0.25, P=0.03)$ were independently associated with the change in $\mathrm{E} / \mathrm{A}$ ratio.

Conclusion: Treatment with olmesartan/azelnidipine for 2 years resulted in greater improvements in CBP, LVMI, and LV diastolic function, and arterial stiffness compared with olmesartan/amlodipine. Improvements in LV diastolic function were associated with improvements in arterial stiffness.

Keywords: central blood pressure, arterial stiffness, left ventricular mass index, left ventricular diastolic function, olmesartan/azelnidipine

\section{Introduction}

When blood pressure (BP) control is inadequate with a single antihypertensive drug, the use of two or three drugs in combination is often necessary to achieve the target blood pressure. Combination therapy with an angiotensin II receptor blocker (ARB) and a diuretic or an ARB plus a calcium $\left(\mathrm{Ca}^{2+}\right)$ channel blocker $(\mathrm{CCB})$ are recommended in the current Japanese Society for Hypertension guidelines. ${ }^{1}$

Several studies, ${ }^{2-4}$ including the Conduit Artery Function Evaluation substudy of the Anglo-Scandinavian Cardiac Outcomes Trial (ASCOT-CAFE) ${ }^{3}$ have emphasized the importance of targeting central blood pressure (CBP) rather than brachial BP
Correspondence: Takeshi Takami Department of Internal Medicine, Clinic Jingumae, 5-4-4I Naizencho, Kashihara, Nara 634-0804, Japan

Tel +8I 744238568

Fax +81744236818

Email takami66@m5.kcn.ne.jp 
in terms of cardiovascular disease outcomes. Additionally, it was reported that an $\mathrm{ARB}$ in combination with a $\mathrm{CCB}$ significantly improves CBP more than an ARB in combination with a diuretic. ${ }^{4}$ We previously reported that 24 weeks of combination therapy with olmesartan plus azelnidipine had greater effects on CBP and left ventricular (LV) mass index (LVMI) than did olmesartan plus amlodipine, even though the reduction in brachial BP was similar in both groups. ${ }^{5}$ We also detected a strong correlation between the change in CBP and the change in LVMI $\left(R^{2}=0.626\right.$, $P<0.001)$. However, it was unknown whether the observed effects of olmesartan/azelnidipine on CBP and LVMI were long-lasting.

Our earlier study assessed LV hypertrophy but not LV diastolic function. LV hypertrophy ${ }^{6}$ and LV diastolic dysfunction $^{7}$ are often associated with hypertension, and arterial stiffness is often aggravated in hypertensive patients. ${ }^{8}$ Considering this issue, it is important that the effects of antihypertensive drugs on LV hypertrophy and LV diastolic dysfunction are fully evaluated and compared among different classes of antihypertensive drugs.

To date, very few studies have compared the long-term outcomes of different antihypertensive drug regimens on LV diastolic function or arterial stiffness. Therefore, we hypothesized that the combination of olmesartan plus azelnidipine would have greater long-term effects on cardiac function than the combination of olmesartan plus amlodipine. To test this hypothesis, we conducted a 2-year, prospective, randomized, open-label, parallel-group study (AORTA II study, Azelnidipine plus OlmesaRTAn versus amlodipine plus olmesartan) to compare the effects of olmesartan/ azelnidipine and olmesartan/amlodipine on clinic-measured $\mathrm{BP}$, heart rate (HR), CBP, LV hypertrophy, LV diastolic function, and arterial stiffness. Hypertensive patients who failed to achieve a target blood pressure following 12 weeks of olmesartan monotherapy were randomized to receive either olmesartan/azelnidipine or olmesartan/amlodipine for 2 years. We also sought to identify the factors associated with improvements in LV hypertrophy and LV diastolic function. As indices of arterial stiffness and wave reflections, we measured the brachial-ankle pulse wave velocity (baPWV) and the augmentation index (AIx, normalized for a HR of $75 \mathrm{bpm}$ ). LV hypertrophy was determined as the LVMI, while LV dysfunction was measured in terms of $\mathrm{e}^{\prime}$, $\mathrm{E} / \mathrm{e}^{\prime}$ ratio, and $\mathrm{E} / \mathrm{A}$ ratio. All of these factors are known to be altered in hypertensive patients and predict stroke ${ }^{9,10}$ or other serious clinical outcomes. ${ }^{11,12}$

\section{Methods}

\section{Patients}

As previously described, ${ }^{5}$ hypertensive outpatients (with or without current therapy) aged 36-75 years were consecutively recruited at the Department of Internal Medicine at Clinic Jingumae (Kashihara, Japan) between March 2007 and January 2010. Hypertension was defined as clinic-measured systolic BP $(\mathrm{SBP}) \geq 140 \mathrm{mmHg}$ and/or diastolic BP $(\mathrm{DBP}) \geq 90 \mathrm{mmHg}$ on two different occasions. Patients on current antihypertensive therapy were also defined as having hypertension. Patients were excluded for any of the following reasons: current treatment with olmesartan, secondary hypertension, arrhythmia, current treatment for congestive heart failure, history of stroke or coronary artery disease, clinically significant valvular heart disease, renal insufficiency (serum creatinine $\geq 2 \mathrm{mg} / \mathrm{dL}$ ), mental disorders, severe noncardiovascular disease (eg, cancer or liver cirrhosis), or chronic inflammatory disease. Patients with clinicmeasured $\mathrm{SBP}>200 \mathrm{mmHg}$ and/or DBP $>115 \mathrm{mmHg}$ at any time during the run-in period were withdrawn from the study. All of the patients provided written informed consent. The study protocol was approved by the Institutional Ethical Committee of Nara Medical University.

\section{Study design}

The AORTA II study was designed as a 2-year, prospective, randomized, open-label parallel-group study (Figure 1). It consisted of a 12-week run-in period and a 2-year randomized treatment period. During the run-in period, patients were treated with olmesartan alone (20 mg/daily). Patients already on antihypertensive drugs were switched to olmesartan monotherapy at the start of the run-in period. After the 12 -week run-in period, patients with a clinic-measured $\mathrm{SBP} \geq 140 \mathrm{mmHg}$ and/or DPB $\geq 90 \mathrm{mmHg}$ were randomized (1:1) using the permuted block method to receive either azelnidipine (16 mg/day) or amlodipine ( $5 \mathrm{mg} /$ day) as addon to ongoing olmesartan. Both regimens were continued at fixed doses, without dose titration, for 2 years. The patients were instructed to take their medications after breakfast and were not permitted to use any other antihypertensive drugs. Drugs (eg, azole antifungal drugs and protease inhibitors) that had the potential to interfere with the safety or efficacy of the study drugs were not permitted during the study. The following were measured at baseline, at 6 months, and at 2 years of treatment: brachial BP, HR, CBP, AIx, baPWV, LVMI, and LV diastolic function ( $\mathrm{e}^{\prime}, \mathrm{E} / \mathrm{e}^{\prime}$ ratio, and $\mathrm{E} / \mathrm{A}$ ratio). There were no modifications to the methods or outcomes after 


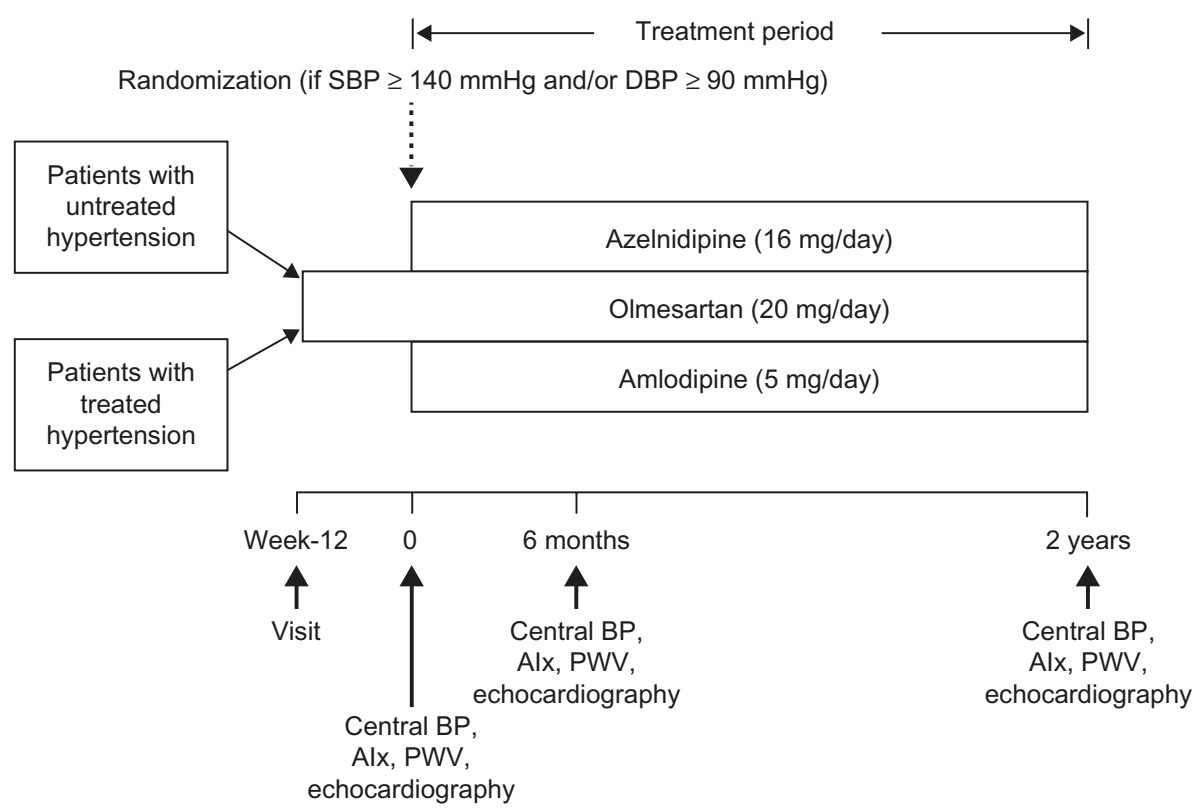

Figure I Study protocol.

Modified with permission from Takami T, Saito Y. Effects of azelnidipine plus olmesartan versus amlodipine plus olmesartan on central blood pressure and left ventricular mass index: the AORTA study. Vasc Health Risk Manag. 383-390. (C) 2012 Dove Medical Press. ${ }^{5}$

Abbreviations: SBP, systolic blood pressure; DBP, diastolic blood pressure; CBP, central blood pressure; Alx, augmentation index; PWV, pulse wave velocity; LVMI, left ventricular mass index.

starting the study. The randomization list was prepared by a medical secretary at Clinic Jingumae and was sent to the investigators in opaque envelopes to conceal randomization order and allocation.

\section{Measurement of CBP,Alx, and baPWV}

$\mathrm{CBP}, \mathrm{AIx}$, and baPWV were measured as previously described. ${ }^{5}$ An automated tonometry system (HEM-9000AI; Omron Healthcare, Kyoto, Japan) was used to record the pulse pressure waveform of the radial artery with the patient in the sitting position after $\mathrm{a} \geq 5 \mathrm{~min}$ rest. The first and second systolic pressure components (SBP1 and SBP2) were determined from the pulse pressure waveform. As SBP2 is similar to invasively measured aortic $\mathrm{CBP},{ }^{13}$ it was used as an estimate of CBP. The HEM9000-AI-measured CBP was similar to CBP estimated using a generalized aorta-radial transfer function. ${ }^{14-16}$ The AI was calculated using the formula $(\mathrm{SBP} 2-\mathrm{DBP}) /(\mathrm{SBP} 1-\mathrm{DBP}) \times 100$, and was normalized for an HR of 75 bpm (AIx) because it is influenced by the HR. ${ }^{17}$

Arterial stiffness was measured as baPWV, as previously described. ${ }^{5,18}$ Pulse waveforms of both forearms and both ankles were obtained after the patient had rested in the supine position for $\geq 5 \mathrm{~min}$ and were used to determine the baPWV. The deviation between two repeated measurements of baPWV was $<5 \%$. The mean value on the right side was used for each patient.

\section{Measurement of LVMI and LF diastolic function}

Standard M-mode echocardiography with two-dimensional guidance and a 3-MHz transducer (Vivid S6 ultrasound system; GE Healthcare, Milwaukee, WI, USA) was performed to determine LVMI using the formula reported by Devereux et al. ${ }^{18}$ From the mitral flow velocity pattern, we measured the peak velocities of the $\mathrm{E}$ and $\mathrm{A}$ waves on mitral flow velocity, and calculated the ratio of their peak velocities (E/A ratio). Doppler tissue integration of longitudinal mitral annular velocity was recorded at the septal annulus in the apical four-chamber view throughout the cardiac cycle. The peak early diastolic ( $\left.\mathrm{e}^{\prime}\right)$ myocardial velocities, $\mathrm{e}^{\prime}$ velocity, and

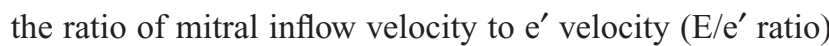
were measured as previously described. ${ }^{19}$

\section{Sample size calculation}

The AORTA II study was designed to show a difference in the decrease in central blood pressure (measured in $\mathrm{mmHg}$ ) between olmesartan/azelnidipine and olmesartan/amlodipine treatment. With the assumption of a standard deviation (SD) of $5.0 \mathrm{mmHg}$ and mean difference of $4.0 \mathrm{mmHg}$ between the two groups and a power of 0.8 at a one-sided significance level of 0.025 , at least 30 patients were required in each treatment group. To account for possible withdrawals, we planned to enroll at least 60 patients (30 per group). 


\section{Statistical analysis}

Data are shown as means \pm SD. Differences between the two groups at baseline were analyzed using unpaired $t$ tests for continuous variables and $\chi^{2}$ tests for categorical variables. Repeated-measures ANOVAs with Dunnett's adjustment were used for within-group comparisons. A between-group time course comparison was performed using an analysis of group-by-time interactions by repeated-measures ANOVA. Pearson's methods were used to assess correlations among the changes in LVMI, E/e' ratio, E/A ratio, and other variables. Variables with a $P$-value $<0.05$ in univariate analyses were entered into multivariate linear regression analysis with stepwise variable selection to identify the factors that were independently associated with the changes in LVMI ratio, $\mathrm{E} / \mathrm{e}^{\prime}$ ratio, and $\mathrm{E} / \mathrm{A}$ ratio at 2 years.

Univariate and multivariate correlation and regression analyses were conducted in the total population. Differences were considered statistically significant at values of $P<0.05$.

\section{Results}

The first patient entered the study in March 2007 and the last patient completed the study in accordance with the study protocol in January 2012. As previously reported, ${ }^{5} 113$ patients entered the run-in period, of which 54 were randomized to receive add-on azelnidipine $(n=27)$ or amlodipine $(n=27)$. One patient in each group was excluded from the assessments performed at 6 months as both of the patients missed the assessment visits (Figure 2). One patient in the olmesartan/azelnidipine group and one patient in the olmesartan/amlodipine group withdrew from the study between 6 months and 2 years because they did not return to our clinic. However, these patients were followed up at another clinic and did not experience any adverse events. Therefore, 26 patients in each group were included in the present analyses. As shown in Table 1, the two groups were well matched, as their baseline characteristics were similar, with no significant differences in any of the factors determined at baseline.

Table 2 shows the changes in parameters assessed at 6 months and 2 years of treatment in the olmesartan/azelnidipine and olmesartan/amlodipine groups. SBP, DBP, CBP, AIx (AI normalized for a heart rate of $75 \mathrm{bpm}$ ), baPWV, LVMI, and E/e' ratio decreased significantly while $\mathrm{e}^{\prime}$ velocity and $\mathrm{E} / \mathrm{A}$ ratio increased significantly in both groups from baseline to 6 months and 2 years of treatment. The changes

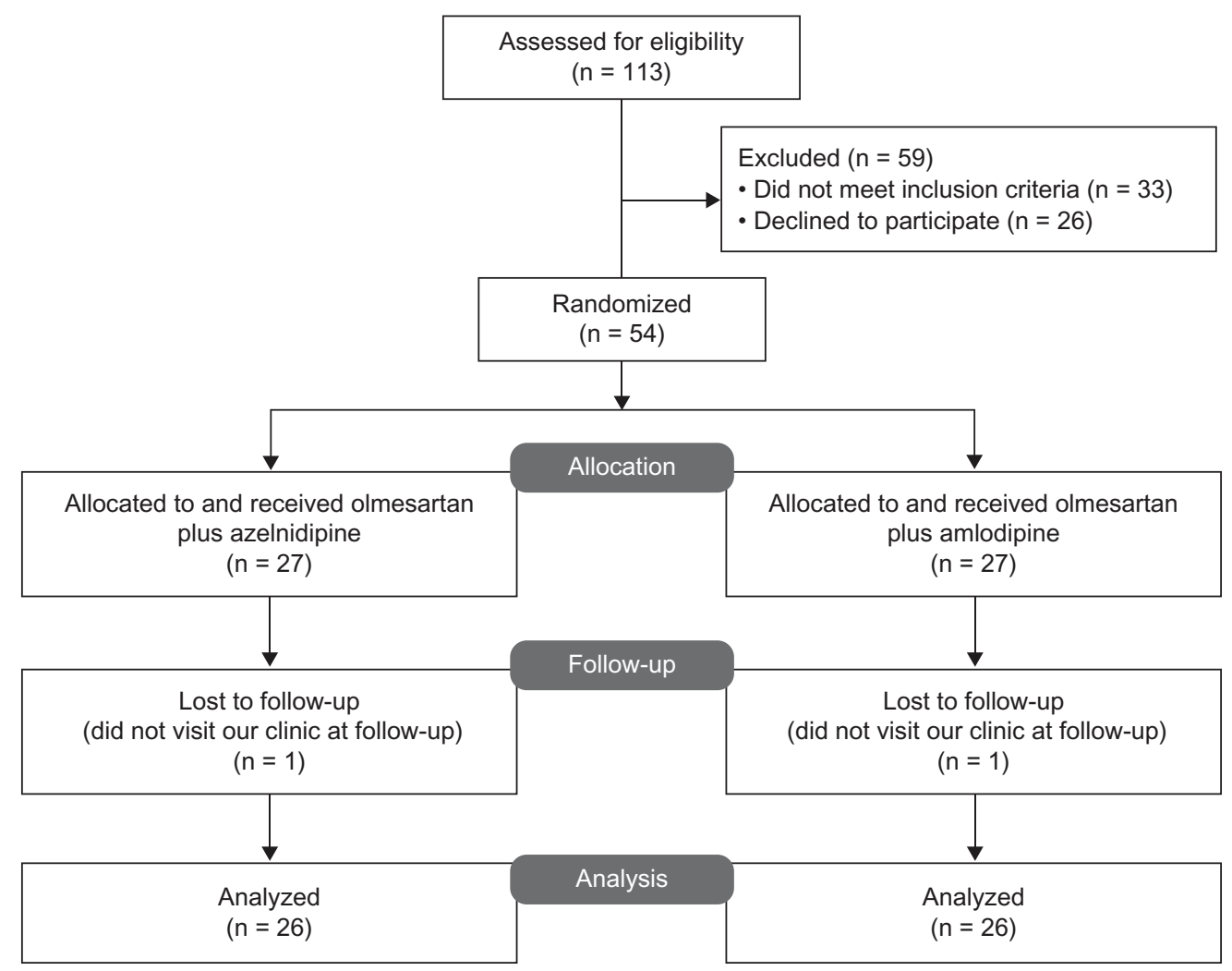

Figure 2 Patient disposition. 
Table I Patient characteristics at baseline

\begin{tabular}{|c|c|c|c|}
\hline & $\begin{array}{l}\text { Olmesartan } \\
\text { plus azelnidipine } \\
(n=26)\end{array}$ & $\begin{array}{l}\text { Olmesartan } \\
\text { plus amlodipine } \\
(n=26)\end{array}$ & $P$ \\
\hline Sex (male/female) & $17 / 9$ & $19 / 7$ & 0.55 \\
\hline Age (years) & $66.2 \pm 4.4$ & $67.5 \pm 4.5$ & 0.26 \\
\hline $\mathrm{SBP}(\mathrm{mmHg})$ & $151.8 \pm 5.5$ & $151.9 \pm 4.5$ & 0.96 \\
\hline $\mathrm{DBP}(\mathrm{mmHg})$ & $85.8 \pm 5.1$ & $86.1 \pm 4.6$ & 0.82 \\
\hline Heart rate (bpm) & $73.7 \pm 5.7$ & $73.7 \pm 6.9$ & 1.00 \\
\hline Central BP (mmHg) & $147.4 \pm 5.3$ & $146.4 \pm 3.5$ & 0.42 \\
\hline Alx (\%) & $92.0 \pm 4.4$ & $92.6 \pm 3.3$ & 0.55 \\
\hline $\mathrm{baPWV}(\mathrm{cm} / \mathrm{s})$ & $1890.7 \pm 198.7$ & $1845.9 \pm 170.9$ & 0.39 \\
\hline LVMI $\left(g / m^{2}\right)$ & $123.0 \pm 3.3$ & $123.0 \pm 2.9$ & 0.93 \\
\hline $\mathrm{e}^{\prime}(\mathrm{cm} / \mathrm{s})$ & $8.2 \pm 0.6$ & $8.2 \pm 0.5$ & 0.90 \\
\hline E/e' ratio & $12.3 \pm 1.2$ & $12.0 \pm 1.2$ & 0.35 \\
\hline E/A ratio & $0.79 \pm 0.07$ & $0.79 \pm 0.11$ & 0.88 \\
\hline $\mathrm{EF}(\%)$ & $64.5 \pm 2.5$ & $65.5 \pm 1.9$ & 0.12 \\
\hline eGFR $\left(\mathrm{mL} / \mathrm{min} / \mathrm{l} .73 \mathrm{~m}^{2}\right)$ & $66.3 \pm 4.5$ & $66.4 \pm 4.0$ & 0.90 \\
\hline $\mathrm{HbA}_{\mathrm{Ic}}(\%)$ & $5.7 \pm 1.1$ & $5.8 \pm 1.2$ & 0.91 \\
\hline LDL (mg/dL) & $112.2 \pm 12.1$ & $110.3 \pm 16.2$ & 0.64 \\
\hline $\mathrm{HDL}(\mathrm{mg} / \mathrm{dL})$ & $55.4 \pm 8.1$ & $56.0 \pm 8.8$ & 0.81 \\
\hline TG (mg/dL) & $170.7 \pm 60.6$ & $154.0 \pm 74.2$ & 0.38 \\
\hline UA (mg/dL) & $5.6 \pm 0.8$ & $5.4 \pm 1.0$ & 0.58 \\
\hline BMI $\left(\mathrm{kg} / \mathrm{m}^{2}\right)$ & $25.7 \pm I . I$ & $25.8 \pm 1.3$ & 0.85 \\
\hline Diabetes, $\mathrm{n}$ & 9 & 7 & 0.55 \\
\hline
\end{tabular}

Note: Values are means \pm SD.

Abbreviations: eGFR, estimated glomerular filtration rate; $\mathrm{Hb} \mathrm{A}_{1 \mathrm{c}}$, hemoglobin $\mathrm{A}_{1 \mathrm{c}}$; LDL, low-density lipoprotein; HDL, high-density lipoprotein; TG, triglycerides; $\mathrm{UA}$, uric acid; BMI, body mass index.

in HR, CBP, AIx, baPWV, LVMI, E/A ratio, and E/e' ratio over 2 years were significantly greater in the olmesartan/ azelnidipine group than in the olmesartan/amlodipine group throughout the 2-year period $(P<0.001, P<0.001$, $P<0.001, P<0.001, P<0.001, P=0.03$, and $P=0.002$ for time $\times$ group interactions for HR, CBP, AIx, baPWV, LVMI, E/e' ratio, and E/A ratio, respectively). Table 3 shows the results of the univariate and multivariate analyses that were performed to identify the factors associated with the reduction in LVMI in the total population. Univariate analysis showed that the change in LVMI was significantly correlated with changes in HR, CBP, AIx, baPWV, e' velocity, E/e' ratio, and $\mathrm{E} / \mathrm{A}$ ratio. In stepwise multivariate linear regression, the changes in CBP $(\beta=0.47, P=0.01)$ and baPWV $(\beta=0.41$, $P<0.001)$ were independently associated with the change in LVMI. In analyses stratified by treatment group, the change in baPWV was independently associated with the change in LVMI in both groups (olmesartan/azelnidipine: $\beta=0.49$, $P<0.001$; olmesartan/amlodipine: $\beta=0.44, P<0.001$ ). Although the change in AIx was also associated with the change in LVMI, multivariate analysis revealed that LVMI was more strongly correlated with baPWV than AIx.
Table 2 Changes in hemodynamic parameters

\begin{tabular}{|c|c|c|c|}
\hline & $\begin{array}{l}\text { Olmesartan } \\
\text { plus azelnidipine } \\
(n=26)\end{array}$ & $\begin{array}{l}\text { Olmesartan } \\
\text { plus amlodipine } \\
(n=26)\end{array}$ & $\begin{array}{l}P \text { (time } \times \\
\text { group } \\
\text { interaction) }\end{array}$ \\
\hline \multicolumn{4}{|l|}{$\mathrm{SBP}(\mathrm{mmHg})$} \\
\hline Baseline & $151.8 \pm 5.5$ & $151.9 \pm 4.5$ & \\
\hline 6 months & $136.7 \pm 3.1 * * *$ & $137.4 \pm 3.3^{* * *}$ & \\
\hline 2 years & $134.7 \pm 4.5^{* * *}$ & $132.5 \pm 5.6 * * *$ & 0.17 \\
\hline \multicolumn{4}{|l|}{ DBP (mmHg) } \\
\hline Baseline & $85.8 \pm 5.1$ & $86.1 \pm 4.6$ & \\
\hline 6 months & $82.7 \pm 3.5^{* * *}$ & $83.7 \pm 3.4 * *$ & \\
\hline 2 years & $82.9 \pm 3.6 * * *$ & $82.4 \pm 3.6 * * *$ & 0.26 \\
\hline \multicolumn{4}{|c|}{ Heart rate (bpm) } \\
\hline Baseline & $73.7 \pm 5.7$ & $73.7 \pm 6.9$ & \\
\hline 6 months & $69.1 \pm 4.7^{* * * *}$ & $74.8 \pm 5.8$ & \\
\hline 2 years & $67.4 \pm 4.3^{* * *}$ & $75.5 \pm 7.1^{*}$ & $<0.001$ \\
\hline \multicolumn{4}{|c|}{ Central BP (mmHg) } \\
\hline Baseline & $147.4 \pm 5.3$ & $146.4 \pm 3.5$ & \\
\hline 6 months & $133.2 \pm 4.2^{* * * *}$ & $138.2 \pm 2.6 * * *$ & \\
\hline 2 years & $|3| .4 \pm 3.2^{* * *}$ & $137.8 \pm 2.9 * * *$ & $<0.001$ \\
\hline \multicolumn{4}{|l|}{ Alx (\%) } \\
\hline Baseline & $92.0 \pm 4.4$ & $92.6 \pm 3.3$ & \\
\hline 6 months & $83.5 \pm 2.7^{* * *}$ & $88.5 \pm 3.3 * * *$ & \\
\hline 2 years & $83.0 \pm 2.7^{* * * *}$ & $87.5 \pm 3.6 * * *$ & $<0.001$ \\
\hline \multicolumn{4}{|c|}{ baPWV $(\mathrm{cm} / \mathrm{s})$} \\
\hline Baseline & $1890.7 \pm 198.7$ & $1845.9 \pm 170.9$ & \\
\hline 6 months & $1621.3 \pm 156.7^{* * *}$ & $|745.8 \pm| 44.5^{* * * *}$ & \\
\hline 2 years & $1569.9 \pm 131.2 * * *$ & $1739.6 \pm 144.0 * * *$ & $<0.001$ \\
\hline \multicolumn{4}{|l|}{ LVMI $\left(g / m^{2}\right)$} \\
\hline Baseline & $123.0 \pm 3.3$ & $123.0 \pm 2.9$ & \\
\hline 6 months & $116.5 \pm 3.6 * * *$ & $120.0 \pm 2.6 * * *$ & \\
\hline 2 years & $115.5 \pm 3.1 * * *$ & $120.2 \pm 2.8^{* * *}$ & $<0.001$ \\
\hline \multicolumn{4}{|l|}{$\mathrm{e}^{\prime}(\mathrm{cm} / \mathrm{s})$} \\
\hline Baseline & $8.2 \pm 0.6$ & $8.2 \pm 0.5$ & \\
\hline 6 months & $8.8 \pm 0.4^{* * *}$ & $8.7 \pm 0.5^{* * *}$ & \\
\hline 2 years & $8.9 \pm 0.3^{* * *}$ & $8.7 \pm 0.5^{* * *}$ & 0.27 \\
\hline \multicolumn{4}{|l|}{$\mathrm{E} / \mathrm{e}^{\prime}$ ratio } \\
\hline Baseline & $12.3 \pm 1.2$ & $12.0 \pm 1.2$ & \\
\hline 6 months & $10.9 \pm 0.7 * * *$ & $\mathrm{II} . \mathrm{I} \pm 0.8 * * *$ & \\
\hline 2 years & $10.6 \pm 0.9 * * *$ & $11.3 \pm 0.9 * *$ & 0.002 \\
\hline \multicolumn{4}{|l|}{ E/A ratio } \\
\hline Baseline & $0.79 \pm 0.07$ & $0.79 \pm 0.11$ & \\
\hline 6 months & $0.86 \pm 0.04 * * *$ & $0.84 \pm 0.05 * *$ & \\
\hline 2 years & $0.89 \pm 0.03 * * *$ & $0.84 \pm 0.05^{* *}$ & 0.03 \\
\hline \multicolumn{4}{|l|}{$\mathrm{EF}(\%)$} \\
\hline Baseline & $64.5 \pm 2.5$ & $65.5 \pm 1.9$ & \\
\hline 6 months & $64.5 \pm 2.4$ & $64.6 \pm 2.7$ & \\
\hline 2 years & $64.1 \pm 2.6$ & $64.9 \pm 2.7$ & 0.66 \\
\hline
\end{tabular}

Notes: Value are means \pm SD. $* P<0.05 ; * * P<0.01$; and $* * * P<0.001$ vs baseline.

Abbreviations: SBP, systolic blood pressure; DBP, diastolic blood pressure; Alx, augmentation index (Al normalized for an HR of $75 \mathrm{bpm}$ ); baPWV, brachialankle pulse wave velocity; LVMI, left ventricular mass index; e', peak early diastolic mitral annular velocity; E, peak early diastolic transmitral flow; E/e', ratio of $E$ to $e^{\prime} ; A$, peak late diastolic transmitral flow; $E / A$, ratio of $E$ to $A$; $E F$, ejection fraction. 
Table 3 Univariate and multivariate regression analyses for the change in LVMI in all patients and in each treatment group

\begin{tabular}{|c|c|c|c|c|c|c|c|c|c|c|c|c|}
\hline & \multicolumn{4}{|c|}{ All patients } & \multicolumn{4}{|c|}{ Olmesartan plus azelnidipine } & \multicolumn{4}{|c|}{ Olmesartan plus amlodipine } \\
\hline & \multicolumn{2}{|c|}{ Univariate } & \multicolumn{2}{|c|}{ Multivariate } & \multicolumn{2}{|c|}{ Univariate } & \multicolumn{2}{|c|}{ Multivariate } & \multicolumn{2}{|c|}{ Univariate } & \multicolumn{2}{|c|}{ Multivariate } \\
\hline & $r$ & $P$ & $\beta$ & $P$ & $r$ & $\mathbf{P}$ & $\beta$ & $P$ & $r$ & $P$ & $\beta$ & $\mathbf{P}$ \\
\hline$\overline{S B P}$ & 0.18 & 0.21 & & & 0.48 & 0.01 & 0.23 & 0.03 & 0.27 & 0.18 & & \\
\hline DBP & -0.04 & 0.80 & & & 0.18 & 0.38 & & & -0.11 & 0.58 & & \\
\hline HR & 0.50 & $<0.001$ & & & 0.08 & 0.71 & & & 0.23 & 0.25 & & \\
\hline CBP & 0.68 & $<0.001$ & 0.47 & 0.01 & 0.50 & 0.01 & & & 0.34 & 0.09 & & \\
\hline Alx & 0.45 & $<0.001$ & & & 0.61 & 0.001 & & & -0.16 & 0.43 & & \\
\hline baPWV & 0.80 & $<0.001$ & 0.41 & $<0.001$ & 0.71 & $<0.001$ & 0.49 & $<0.001$ & 0.67 & $<0.001$ & 0.44 & $<0.001$ \\
\hline $\mathrm{e}^{\prime}$ & -0.49 & $<0.001$ & & & -0.56 & 0.003 & & & -0.44 & 0.02 & & \\
\hline$E / e^{\prime}$ & 0.58 & $<0.001$ & & & 0.45 & 0.02 & & & 0.43 & 0.03 & & \\
\hline$E / A$ & -0.49 & $<0.001$ & & & -0.55 & 0.003 & & & -0.32 & 0.11 & & \\
\hline $\mathrm{EF}$ & -0.16 & 0.24 & & & -0.26 & 0.20 & & & -0.11 & 0.58 & & \\
\hline Adjusted $R^{2}$ & & & 0.67 & $<0.001$ & & & 0.57 & $<0.001$ & & & 0.42 & $<0.00$ I \\
\hline
\end{tabular}

Abbreviations: SBP, systolic blood pressure; DBP, diastolic blood pressure; Alx, augmentation index (AI normalized for an HR of 75 bpm); baPWV, brachial-ankle pulse wave velocity; LVMI, left ventricular mass index; e', peak early diastolic mitral annular velocity; E, peak early diastolic transmitral flow; E/e', ratio of E to e'; A, peak late diastolic transmitral flow; E/A, ratio of $E$ to $A$; EF, ejection fraction.

Table 4 shows the results of the univariate and multivariate analyses that were performed to detect factors associated with the reduction in $\mathrm{E} / \mathrm{e}^{\prime}$ ratio. Analysis of the entire study population showed that the change in the $\mathrm{E} / \mathrm{e}^{\prime}$ ratio was significantly correlated with the changes in HR, CBP, AIx, baPWV, and LVMI. Stepwise linear regression analysis showed the change in baPWV was independently associated with the change in the $\mathrm{E} / \mathrm{e}^{\prime}$ ratio $(\beta=0.25, P<0.001)$. In analyses stratified by treatment group, the change in baPWV was independently associated with the change in the $\mathrm{E} / \mathrm{e}^{\prime}$ ratio in the olmesar$\tan /$ azelnidipine group $(\beta=0.35, P=0.001)$ but not in the olmesartan/amlodipine group.

Table 5 shows the results of the univariate and multivariate analyses that were performed to identify factors associated with the change in the E/A ratio. Univariate analyses showed that the change in E/A ratio was significantly correlated with the changes in HR, CBP, AIx, baPWV, and LVMI.
Stepwise linear regression analysis showed that changes in baPWV $(\beta=0.21, P=0.001)$ and AIx $(\beta=0.25, P=0.03)$ were independently associated with the change in the $\mathrm{E} / \mathrm{A}$ ratio. In analyses stratified by treatment group, the change in baPWV was independently associated with the change in $\mathrm{E} / \mathrm{A}$ ratio in both groups (olmesartan/azelnidipine: $\beta=0.34$, $P=0.002$, olmesartan/amlodipine: $\beta=0.27, P=0.01$ ).

No serious adverse events requiring study discontinuation were reported in either treatment group. One patient experienced mild hepatic dysfunction and another experienced vertigo (both in the olmesartan/amlodipine group). Both patients recovered after appropriate therapies.

\section{Discussion}

In the present study, we extended on our previous findings by showing that the improvements in CBP, AIx, baPWV, LVMI, E/e', and E/A ratio were maintained at 2 years, and

Table 4 Univariate and multivariate regression analyses of the change in E/e' ratio in all patients and in each treatment group

\begin{tabular}{|c|c|c|c|c|c|c|c|c|c|c|c|c|}
\hline & \multicolumn{4}{|c|}{ All patients } & \multicolumn{4}{|c|}{ Olmesartan plus azelnidipine } & \multicolumn{4}{|c|}{ Olmesartan plus amlodipine } \\
\hline & \multicolumn{2}{|c|}{ Univariate } & \multicolumn{2}{|c|}{ Multivariate } & \multicolumn{2}{|c|}{ Univariate } & \multicolumn{2}{|c|}{ Multivariate } & \multicolumn{2}{|c|}{ Univariate } & \multicolumn{2}{|c|}{ Multivariate } \\
\hline & $r$ & $\boldsymbol{P}$ & $\beta$ & $\boldsymbol{P}$ & $r$ & $\boldsymbol{P}$ & $\beta$ & $\mathbf{P}$ & $r$ & $\boldsymbol{P}$ & $\beta$ & $P$ \\
\hline SBP & 0.09 & 0.55 & & & 0.15 & 0.47 & & & 0.19 & 0.35 & & \\
\hline DBP & -0.02 & 0.88 & & & -0.002 & 0.99 & & & 0.05 & 0.82 & & \\
\hline HR & 0.46 & 0.001 & 0.22 & 0.15 & 0.25 & 0.21 & & & 0.30 & 0.14 & & \\
\hline CBP & $0.4 I$ & 0.003 & & & 0.22 & 0.28 & & & 0.10 & 0.63 & & \\
\hline Alx & $0.4 \mathrm{I}$ & 0.002 & & & 0.33 & 0.10 & & & 0.26 & 0.20 & & \\
\hline baPWV & 0.62 & $<0.001$ & 0.25 & $<0.001$ & 0.59 & 0.001 & 0.35 & 0.001 & 0.43 & 0.03 & & \\
\hline LVMI & 0.58 & $<0.001$ & & & 0.45 & 0.02 & & & 0.43 & 0.03 & 0.18 & 0.031 \\
\hline $\mathrm{EF}$ & -0.10 & 0.49 & & & 0.28 & 0.16 & & & -0.51 & 0.008 & 0.26 & 0.009 \\
\hline Adjusted $R^{2}$ & & & 0.39 & $<0.001$ & & & 0.33 & 0.001 & & & 0.34 & 0.003 \\
\hline
\end{tabular}

Abbreviations: SBP, systolic blood pressure; DBP, diastolic blood pressure; Alx, augmentation index (Al normalized for an HR of 75 bpm); baPWV, brachial-ankle pulse wave velocity; LVMI, left ventricular mass index; EF, ejection fraction; E/e', ratio of $E$ to $e^{\prime}$. 
Table 5 Univariate and multivariate regression analyses of the change in E/A ratio in all patients and in each treatment group

\begin{tabular}{|c|c|c|c|c|c|c|c|c|c|c|c|c|}
\hline & \multicolumn{4}{|c|}{ All patients } & \multicolumn{4}{|c|}{ Olmesartan plus azelnidipine } & \multicolumn{4}{|c|}{ Olmesartan plus amlodipine } \\
\hline & \multicolumn{2}{|c|}{ Univariate } & \multicolumn{2}{|c|}{ Multivariate } & \multicolumn{2}{|c|}{ Univariate } & \multicolumn{2}{|c|}{ Multivariate } & \multicolumn{2}{|c|}{ Univariate } & \multicolumn{2}{|c|}{ Multivariate } \\
\hline & $r$ & $P$ & $\beta$ & $P$ & $r$ & $P$ & $\beta$ & $P$ & $r$ & $P$ & $\beta$ & $P$ \\
\hline$\overline{\mathrm{SBP}}$ & -0.15 & 0.28 & & & -0.31 & 0.13 & & & -0.16 & 0.43 & & \\
\hline DBP & -0.01 & 0.93 & & & -0.01 & 0.95 & & & -0.06 & 0.75 & & \\
\hline $\mathrm{HR}$ & -0.36 & 0.01 & & & -0.27 & 0.19 & & & -0.21 & 0.31 & & \\
\hline CBP & -0.50 & $<0.001$ & & & -0.44 & 0.02 & 0.20 & 0.14 & -0.45 & 0.02 & & \\
\hline Alx & -0.50 & $<0.001$ & 0.25 & 0.03 & -0.52 & 0.007 & & & -0.40 & 0.04 & 0.16 & 0.02 \\
\hline baPWV & -0.59 & $<0.001$ & 0.21 & 0.001 & -0.65 & $<0.001$ & 0.34 & 0.002 & -0.47 & 0.01 & 0.27 & 0.01 \\
\hline LVMI & -0.49 & $<0.001$ & & & -0.55 & 0.003 & & & -0.32 & 0.11 & & \\
\hline $\mathrm{EF}$ & 0.02 & 0.89 & & & -0.08 & 0.69 & & & 0.09 & 0.67 & & \\
\hline Adjusted $R^{2}$ & & & 0.38 & $<0.001$ & & & 0.42 & $<0.001$ & & & 0.33 & 0.004 \\
\hline
\end{tabular}

Abbreviations: SBP, systolic blood pressure; DBP, diastolic blood pressure; Alx, augmentation index (Al normalized for an HR of 75 bpm); baPWV, brachial-ankle pulse wave velocity; LVMI, left ventricular mass index; EF, ejection fraction.

continued to be significantly greater in the olmesartan/azelnidipine group than in the olmesartan/amlodipine group, despite similar reductions in brachial BP in both groups. The results of stepwise multivariate linear regression analysis showed that the reduction in LVMI after 2 years of treatment was directly correlated with the reduction in CBP. Increased CBP causes an increase in LV afterload that can lead to LV hypertrophy. The improvement in LVMI observed in this study appears to have resulted from the reduction in CBP. The reduction in baPWV was also independently associated with the reduction in LVMI. The results of this study suggest that the reduction in baPWV led to a delay in pulse wave reflection and hence reduced cardiac afterload. The results of a previous study revealed associations of AI and baPWV with LVMI. ${ }^{20}$ Specifically, AI as an index of aortic sclerosis is related to aortic distensibility or reflecting waves; however, in the present study, baPWV was found to be an independent factor from LVMI. Therefore, the reduction in baPWV appears to be related to the improvement in LVMI. Although our study included many patients with LV diastolic dysfunction, our current findings are consistent with those of the earlier study showing a correlation between baPWV and LVMI, E/A ratio. ${ }^{20}$

A follow-up study that monitored 1839 hypertensive patients for up to 11 years (mean: 4.4 years) for the onset of cardiovascular events showed that patients with LV diastolic dysfunction were at increased risk for cardiovascular events compared with patients without diastolic dysfunction. ${ }^{21}$ Our study also detected improvements in LV diastolic function and LVMI. The E/e' ratio, defined as the ratio of peak early LV filling velocity to peak early diastolic mitral annular velocity, is considered to reflect pulmonary arterial wedge pressure regardless of the severity of LV systolic dysfunction.
$\mathrm{E} / \mathrm{e}^{\prime}$ is used as an index for $\mathrm{LV}$ end-diastolic pressure. It is reported that in cases of $\mathrm{E} / \mathrm{e}^{\prime} \leq 8, \mathrm{LV}$ end-diastolic pressure is low and in cases of $E / \mathrm{e}^{\prime} \geq 15, \mathrm{LV}$ end-diastolic pressure is high. ${ }^{22}$ Thus, the $\mathrm{E} / \mathrm{e}^{\prime}$ ratio is widely used as a prognostic predictor in clinical treatment. ${ }^{23}$ We previously reported that olmesartan/azelnidipine antihypertensive therapy achieved greater reductions in HR, baPWV, and AIx than did olmesartan/amlodipine therapy at 24 weeks, and thus achieved greater improvements in arterial stiffness. ${ }^{5}$ The first new finding of the present study is that the $\mathrm{E} / \mathrm{e}^{\prime}$ ratio showed greater improvements in the olmesartan/azelnidipine group than in the olmesartan/amlodipine group throughout the 2-year study period. The second new finding is that baPWV, an indicator of arterial stiffness, was independently associated with the reduction in the $\mathrm{E} / \mathrm{e}^{\prime}$ ratio $(P<0.001)$, suggesting baPWV is a useful indicator of LV diastolic function. In analyses stratified by treatment group, the reduction in baPWV was independently associated with the reduction in the $\mathrm{E} / \mathrm{e}^{\prime}$ ratio in the olmesartan/azelnidipine group, but not the olmesartan/ amlodipine group. In brief, this is thought to be attributable to the greater improvement in arterial stiffness in the olmesartan/azelnidipine group than in the olmesartan/amlodipine group. A recent cohort study ${ }^{24}$ that assessed asymptomatic LV diastolic dysfunction by tissue Doppler imaging revealed that aggravated arterial stiffness was linked to aggravated LV diastolic dysfunction.

The present study also revealed that a reduction in the $\mathrm{E} / \mathrm{A}$ ratio was an indicator of $\mathrm{LV}$ diastolic dysfunction, and that the change in baPWV was independently associated with the change in $\mathrm{E} / \mathrm{A}$ ratio. It was previously reported that, even if the $\mathrm{E} / \mathrm{A}$ ratio is corrected for age in hypertensive patients, baPWV is an independent predictor for $\mathrm{LV}$ diastolic dysfunction, as is $\mathrm{E} / \mathrm{e}^{\prime}$, so that increases in baPWV may be a risk 
factor for diastolic heart failure. ${ }^{25}$ baPWV was also reported to be an independent risk factor for LV diastolic dysfunction in untreated hypertensive patients. ${ }^{26}$ Additionally, a cohort study of Chinese patients with LV diastolic dysfunction showed a significant correlation between PWV and the E/A ratio based on multivariate linear regression analysis. ${ }^{27}$

An experimental study in mice suggested that a reduction in HR may improve vascular stiffness and consequently lead to improvements in LV diastolic function. ${ }^{28}$ An experimental study also showed that azelnidipine dose-dependently reduces $\mathrm{HR} .{ }^{29}$ In another study, azelnidipine suppressed cardiac hypertrophy, fibrosis, NADPH oxidase, and superoxide levels in stroke-prone spontaneously hypertensive rats more potently than did amlodipine, and was associated with lower HR than was amlodipine. ${ }^{30}$

Hypertension is associated with oxidative stress, which impairs vascular endothelial function and, together with other factors, may increase arterial stiffness. However, increasing arterial stiffness, which may be caused by a variety of factors, could be a cause of hypertension in some patients. ${ }^{31}$ Drugs that reduce cardiac afterload are thought to effectively control hypertension by reducing cardiac load. Dihydropyridine CCBs that have vasodilating and antioxidant activities are representative medications that can reduce the cardiac load by dilating the peripheral capillary vessels, although the effects of their antioxidant activities in patients with hypertension are largely unknown.

In patients who switched from amlodipine to azelnidipine, BP and HR decreased significantly, and these reductions were associated with an increase in the $\mathrm{e}^{\prime}$ velocity. ${ }^{32}$ On the basis of this finding, regression of LVMI may be associated with the improvements in LV diastolic function elicited by azelnidipine. Furthermore, aortic stiffness increases central SBP and LV afterload, leading to LV myocyte hypertrophy. Diastolic dysfunction may be due to impaired relaxation resulting from the cardiac changes described above. Alternatively, aortic stiffness reduces central DBP and coronary blood flow, resulting in subendocardial ischemia. Diastolic dysfunction may also occur because of myocardial fibrosis arising from subendocardial ischemia occurring via the pathway described above. ${ }^{33}$ Therefore, olmesartan/azelnidipine antihypertensive therapy appears to play a valuable role in these pathological pathways.

The results of the present study indicate that olmesartan/ azelnidipine is significantly superior to olmesartan/amlodipine in reducing HR and in improving vascular stiffness and diastolic function. Vascular stiffness alone, however, was independently associated with improved diastolic function.
Some limitations of this study should be discussed. First, the present study enrolled a relatively small number of patients. Moreover, the study was not conducted in a doubleblind manner. However, all measurements (AI, LVMI, E/A ratio, e', E/e' ratio, and PWV) were performed by an investigator who was blinded to treatment allocation to avoid bias in these measurements.

\section{Conclusion}

Treatment with olmesartan/azelnidipine for 2 years achieved significantly greater improvements in HR, arterial stiffness, and cardiac hypertrophy compared with olmesartan/ amlodipine therapy. Therefore, the two therapies differed in their effects on improving cardiac hypertrophy and arterial stiffness. Compared with olmesartan/amlodipine, olmesartan/ azelnidipine also achieved significantly greater improvements in LV diastolic dysfunction, which were maintained for 2 years. These results indicate that olmesartan/azelnidipine steadily improves LV diastolic dysfunction during longterm therapy and that the change in arterial stiffness was independently associated with improvements in LV diastolic dysfunction.

\section{Acknowledgments}

We wish to thank N Mune for technical support and A Takemura for secretarial support.

\section{Disclosure}

The authors have no conflicts of interest to declare.

\section{References}

1. Ogihara T, Kikuchi K, Matsuoka H, et al. The Japanese Society of Hypertension Guidelines for the Management of Hypertension (JSH2009). Hypertens Res. 2009;32:3-107.

2. Roman MJ, Devereux, Kizer JR, et al. Central pressure more strongly relates to vascular disease and outcome than dose brachial pressure: the Strong Heart Study. Hypertension. 2007;50:197-203.

3. Williams B, Lacy PS, Thom SM, et al. Differential impact of blood pressure-lowering drugs on central aortic pressure and clinical outcomes: principal results of the Conduct Artery Function Evaluation (CAFE) study. Circulation. 2006;113:1213-1225.

4. Matsui Y, Eguchi K, O'Rourke MF, et al. Differential effects between a calcium channel blocker and a diuretic when used in combination with angiotensin II receptor blocker on central aortic pressure in hypertensive patients. Hypertension. 2009;54:716-723.

5. Takami T, Saito Y. Effects of azelnidipine plus olmesartan versus amlodipine plus olmesartan on central blood pressure and left ventricular mass index: the AORTA study. Vasc Health Risk Manag. 2011;7: 383-390.

6. Massie BM, Tubau JF, Szlachcic J, O’Kelly BF. Hypertensive heart disease: the critical role of left ventricular hypertrophy. $J$ Cardiovasc Pharmacol. 1989;13(Suppl 1):S18-S24.

7. Bonow RO, Udelson JE. LV diastolic dysfunction as a cause of congestive heart failure. Mechanism and management. Ann Intern Med. 1992;117: 502-510. 
8. Asmar R, Rudnichi A, Blacher J, London GM, Safar ME. Pulse pressure and aortic pulse wave are markers of cardiovascular risk in hypertensive populations. Am J Hypertens. 2001;14:91-97.

9. Laurent S, Boutouyrie P. Arterial stiffness and stroke in hypertension: therapeutic implications for stroke prevention. CNS Drugs. 2005;19: $1-11$.

10. Blacher J, Safar ME. Large-artery stiffness, hypertension and cardiovascular risk in older patients. Nat Clin Pract Cardiovasc Med. 2005;2: 450-455.

11. Udelson JE, Konstam MA. Relation between left ventricular remodeling and clinical outcomes in heart failure patients with left ventricular systolic dysfunction. J Card Fail. 2002;8:S465-S471.

12. Wachtell K, Palmieri V, Gerdts E, et al. Prognostic significance of left ventricular diastolic dysfunction in patients with left ventricular hypertrophy and systemic hypertension (the LIFE Study). Am J Cardiol. 2010;106:999-1005.

13. Takazawa K, Kobayashi H, Shindo N, Tanaka N, Yamashina A. Relationship between radial and central arterial pulse wave and evaluation of central aortic pressure using the radial arterial pulse wave Hypertens Res. 2007;30:219-228.

14. Richardson CJ, Maki-Petaja KM, McDonnell BJ, et al. Comparison of estimates of central systolic blood pressure and peripheral augmentation index obtained from the Omron HEM-9000AI and SphygmoCor systems. Artery Res. 2009;3:24-31.

15. Hickson SS, Butlin M, Mir FA, et al. The accuracy of central SBP determined from the second systolic peak of the peripheral pressure waveform. J Hypertens. 2009;27:1784-1788.

16. Hirata K, Kojima I, Momomura SI. Noninvasive estimation of central blood pressure and the augmentation index in the seated position: a validation study of two commercially available methods. J Hypertens. 2013;31:508-515.

17. Wilkinson IB, Mohammad NH, Tyrrell S, et al. Heart rate dependency of pulse pressure amplification and arterial stiffness. Am J Hypertens. 2002;15:24-30.

18. Devereux RB, Palmieri V, Sharpe N, et al. Effects of once-daily angiotensin-converting enzyme inhibition and calcium channel blockade-based antihypertensive treatment regimens on left ventricular hypertrophy and diastolic filling in hypertension: the prospective randomized enalapril study evaluating regression of ventricular enlargement (PRESERVE) trial. Circulation. 2001;104:1248-1254.

19. Safar ME, London GM. Therapeutic studies and arterial stiffness in hypertension: recommendations of the European Society of Hypertension. The Clinical Committee of Arterial Structure and Function. Working Group on Vascular Structure and Function of the European Society of Hypertension. J Hypertens. 2000;18:1527-1535.

20. Xu L, Jiang CQ, Lam TH, et al. Arterial stiffness and left-ventricular diastolic dysfunction: Guangzhou Biobank Cohort Study-CVD. J Hum Hypertens. 2011;25:152-158.
21. Kim MN, Park SM, Shim WJ, et al. The relationship between aortic stiffness and left ventricular dyssynchrony in hypertensive patients with preserved left ventricular systolic function. Clin Exp Hypertens. 2012;34:410-416.

22. Schillaci G, Pasqualini L, Verdecchia P, et al. Prognostic significance of left ventricular diastolic dysfunction in essential hypertension. $J \mathrm{Am}$ Coll Cardiol. 2002;39:2005-2011.

23. Ommen SR, Nishimura RA, Appleton CP, et al. Clinical utility of Doppler echocardiography and tissue Doppler imaging in the estimation of left ventricular filling pressures: A comparative simultaneous Doppler-catheterization study. Circulation. 2000;102:1788-1794.

24. Hillis GS, Møller JE, Pellikka PA, et al. Noninvasive estimation of left ventricular filling pressure by e/ $\mathrm{e}^{\prime}$ is a powerful predictor of survival after acute myocardial infarction. J Am Coll Cardiol. 2004;43:360-367.

25. Yambe M, Tomiyama H, Hirayama Y, et al. Arterial stiffening as a possible risk factor for both atherosclerosis and diastolic heart failure. Hypertens Res. 2004;27:625-631.

26. Jaroch J, Łoboz Grudzień K, Bociąga Z, et al. The relationship of carotid arterial stiffness to left ventricular diastolic dysfunction in untreated hypertension. Kardiol Pol. 2012;70:223-231.

27. Xu L, Jiang CQ, Lam TH, et al. Arterial stiffness and left-ventricular diastolic dysfunction: Guangzhou Biobank Cohort Study-CVD. J Hum Hypertens. 2011;25:152-158.

28. Reil JC, Hohl M, Reil GH, et al. Heart rate reduction by If-inhibition improves vascular stiffness and left ventricular systolic and diastolic function in a mouse model of heart failure with preserved ejection fraction. Eur Heart J. July 24, 2012. [Epub ahead of print.]

29. Fujisawa M, Yorikane R, Chiba S, Koike H. Chronotropic effects of azelnidipine, a slow- and long-acting dihydropyridine-type calcium channel blocker, in anesthetized dogs: a comparison with amlodipine. J Cardiovasc Pharmacol. 2009;53:325-332.

30. Yamamoto E, Lai ZF, Yamashita T, et al. Enhancement of cardiac oxidative stress by tachycardia and its critical role in cardiac hypertrophy and fibrosis. J Hypertens. 2006;24:2057-2069.

31. Tomiyama H, Yamashina A. Arterial stiffness in prehypertension: a possible vicious cycle. J Cardiovasc Transl Res. 2012;5:280-286.

32. Ito $\mathrm{H}$, Ishii $\mathrm{K}$, Iwakura $\mathrm{K}$. Impact of azelnidipine treatment on left ventricular diastolic performance in patients with hypertension and mild diastolic dysfunction: multi-center study with echocardiography. Hypertens Res. 2009;32:895-900.

33. Mottram PM, Haluska BA, Leano R, et al. Relation of arterial stiffness to diastolic dysfunction in hypertensive heart disease. Heart. 2005;91: $1551-1556$.
Drug Design, Development and Therapy

\section{Publish your work in this journal}

Drug Design, Development and Therapy is an international, peerreviewed open-access journal that spans the spectrum of drug design and development through to clinical applications. Clinical outcomes, patient safety, and programs for the development and effective, safe, and sustained use of medicines are a feature of the journal, which

\section{Dovepress}

has also been accepted for indexing on PubMed Central. The manuscript management system is completely online and includes a very quick and fair peer-review system, which is all easy to use. Visit http://www.dovepress.com/testimonials.php to read real quotes from published authors 